UDC 582.28:614.61(470.45)

LBC 28.591(2P-4Вог)

\title{
MYCOBIOTA IN CEMETERIAL AREAS OF VOLGOGRAD CITY
}

\author{
Nadezhda S. Kuragina \\ Volgograd State University, Volgograd, Russian Federation \\ Victoria S. Samokish \\ Volgograd State University, Volgograd, Russian Federation
}

\begin{abstract}
Cemeterial areas are an integral part of any urban ecosystem. The flora of cemeteries is diverse due to the large number of introduced species. This fact also implies species diversity in the macromycete biota, which is of interest for further study. Until now, special studies of mycobiota in cemeteries in Volgograd have not been conducted. We have examined three cemeteries in different districts of Volgograd City. Mushroom collection has been carried out by the route method from September to November 2019. To identify the samples we have applied standard light microscopy methods in the laboratory of Experimental biology of Volgograd State University using the guides of wellknown mycologists. Nikon D3500 SLR camera was used for shooting mushrooms. The collected species are stored in the Mycological herbarium of Volgograd State University. As a result we present an annotated list of cemeteria fungi, including 17 species, such as Agaricus arvensis Schaeff., A. xanthodermus Genev., Auricularia mesenterica (Dicks.) Pers., Coprinellus micaceus (Bull.) Vilgalys, Hopple et Jacq. Johnson, Crucibulum laeve (Huds.) Kambly, Hydroporus marginellus (Pers.) Singer, Lepista personata (Fr.) Cooke, Lycoperdon perlatum Pers., Mycena ssp., Myriostoma coliforme (Dicks.) Corda, Phellinus pomaceus (Pers.) Maire, Pilatotrama ljubarskyi (Pilát) Zmitrovich, Pleurotus ostreatus (Jacq.) P. Kumm., Psathyrella conopilea (Fr.) A. Pearson et Dennis, Pseudoclitocybe cyathiformis (Bull.) Singer, Stropharia melanosperma (Bull.) Gillet, Tulostoma brumale Pers. Each annotation includes the date of collection, data on habitats and substrates inhabited by the species, as well as the occurrence of the species. The last index states 'rare' if we have no more than 5 finds, 'often' - 6-20 finds, 'frequent' $-21-50$ finds, and 'very often' - more than 50 finds. The trophic analysis of the macromycete composition has revealed that all the found species belong to the saprotrophic group. Among them, the largest number of species was recorded on dry and dead wood ( 10 species). The further research of the diversity of fungi in these areas is necessary.
\end{abstract}

Key words: cemeterial areas, Kirovsky district, Central district, Traktorozavodsky district, Volgograd, mycobiota, taxonomic analysis, mycological herbarium.

УДК 582.28:614.61(470.45)

ББК 28.591(2Р-4Вог)

МИКОБИОТА ЦЕМЕТЕРИАЛЬНЫХ ТЕРРИТОРИЙ Г. ВОЛГОГРАДА

\section{Надежда Сергеевна Курагина}

Волгоградский государственный университет, г. Волгоград, Российская Федерация

\section{Виктория Сергеевна Самокиш}

Волгоградский государственный университет, г. Волгоград, Российская Федерация

Аннотация. Цеметериальные территории являются составной частью любых урбоэкосистем. Флора кладбищ разнообразна за счет большого числа интродуцированных видов. Это предполагает и видовое разнообразие в биоте макромицетов, что вызывает интерес для дальнейшего ее изучения. До настоящего времени специальных исследований микобиоты кладбищ г. Волгограда не проводилось. Нами были обследова- 
ны Центральное (Димитриевское) и Алюминиевское кладбища, а также кладбище Кировского района. Сбор грибов проводился маршрутным методом с сентября по ноябрь 2019 г. Идентификация образцов осуществлялась стандартными методами световой микроскопии в лаборатории Экспериментальной биологии Волгоградского государственного университета (ВолГУ) с использованием работ известных микологов. Для съемок грибов применялся зеркальный фотоаппарат NIKON D3500. Собранные виды хранятся в Микологическом гербарии ВолГУ. В статье представлен аннотированный список грибов цеметериев, включающий 17 видов, с указанием данных о местообитаниях и субстратах, заселяемых видом, а также встречаемости вида (редко не более 5 находок, нередко 6-20 находок, часто 21-50 находок, очень часто более 50 находок) и дате сбора. Это такие виды, как Agaricus arvensis Schaeff., A. xanthodermus Genev., Auricularia mesenterica (Dicks.) Pers., Coprinellus micaceus (Bull.) Vilgalys, Hopple et Jacq. Johnson, Crucibulum laeve (Huds.) Kambly, Hydroporus marginellus (Pers.) Singer, Lepista personata (Fr.) Cooke, Lycoperdon perlatum Pers., Mycena ssp., Myriostoma coliforme (Dicks.) Corda, Phellinus pomaceus (Pers.) Maire, Pilatotrama ljubarskyi (Pilát) Zmitrovich, Pleurotus ostreatus (Jacq.) P. Kumm., Psathyrella conopilea (Fr.) A. Pearson et Dennis, Pseudoclitocybe cyathiformis (Bull.) Singer, Stropharia melanosperma (Bull.) Gillet, Tulostoma brumale Pers. Проведен трофический анализ состава макромицетов, согласно которому все найденные виды относятся к сапротрофной группе. Из них наибольшее количество видов было зафиксировано на сухостойной и валежной древесине (10 видов).

Необходимо дальнейшее изучение разнообразия грибов на данных территориях.

Ключевые слова: цеметериальные территории, Кировский район, Центральный район, Тракторозаводский район, город Волгоград, микобиота, таксономический анализ, микологический гербарий.

Введение. Цеметериальные территории являются неотъемлемой частью любых урбоэкосистем. Растительный мир кладбищ разнообразен за счет большого числа интродуцированных видов. Это предполагает и видовое разнообразие в биоте грибов, что вызывает интерес для дальнейшего ее изучения. Специальных микологических исследований цеметериев еще не проводилось. Это и явилось целью данной работы.

Для достижения нашей цели были поставлены следующие задачи:

1) изучить видовой состав микобиты цеметериальных территорий г. Волгограда;

2) проанализировать трофическую структуру макромицетов исследуемой территории;

3) выявить субстратную приуроченность.

Материалы и методы исследования.

Метод полевых исследований

Исследование микобиоты цеметериальных территорий проводилось маршрутным методом в период с сентября по ноябрь 2019 года.

Метод микроскопического анализа

Идентификация образцов осуществлялась методом микроскопического анализа с использованием бинокулярного микроскопа Микмед-5, камеры Levenhuk C510 NG и стандартного набора реактивов (раствор щелочи, реактив Мельцера) в лаборатории Экспериментальной биологии Волгоградского государственного университета (далее ВолГУ). При определении грибов были использованы отечественные и зарубежные определители [120]. Собранные виды грибов хранятся в Микологическом гербарии ВолГУ.

Фотографический метод

Для съемок грибов был использован зеркальный фотоаппарат NIKON D3500.

Результаты и их обсуждения. Ниже представлен аннотированный список макромицетов, выявленных в настоящее время на территории цеметериев города Волгограда.

Названия видов расположены по алфавиту и приведены в соответствии с международной электронной базой данных CABI «Index Fungorum» (www.indexfungorum.org) по состоянию на декабрь 2019 года.

В аннотациях к видам указаны данные о местообитаниях и субстратах, заселяемых видом, а также встречаемости вида (редко не более 5 находок, нередко 6-20 находок, часто 21-50 находок, очень часто более 50 находок) и дате сбора.

Agaricus arvensis Schaeff. на почве, Центральное (Димитриевское) кладбище, нередко, 20.10.2019.

Agaricus xanthodermus Genev. на почве, Центральное (Димитриевское) кладбище, часто, 20.10.2019.

Auricularia mesenterica (Dicks.) Pers. на сухостойном стволе Robinia pseudoacacia L., Центральное (Димитриевское) кладбище, единичная находка, 22.11.2019. 
Coprinellus micaceus (Bull.) Vilgalys, Hopple et Jacq. Johnson на пне лиственного дерева, Алюминиевское кладбище, нередко, 13.10.2019.

Crucibulum laeve (Huds.) Kambly на валежных ветвях, Центральное (Димитриевское) кладбище, редко, 20.10.2019.

Hydroporus marginellus (Pers.) Singer на гнилой замшелой древесине, Центральное (Димитриевское) кладбище, нередко, 20.10.2019.

Lepista personata (Fr.) Cooke на почве, Центральное (Димитриевское) кладбище, редко, 20.10.2019.

Lycoperdon perlatum Pers. на почве, Центральное (Димитриевское) кладбище, редко, 20.10.2019.

Mycena ssp. на гнилой замшелой древесине, Центральное (Димитриевское) кладбище, нередко, 20.10.2019.

Myriostoma coliforme (Dicks.) Corda на почве, кладбище Кировского района, единичная находка, 12.10.2019.

Phellinus pomaceus (Pers.) Maire на сухостойном стволе Prunus armeniaca L., кладбище Кировского района, единичная находка, 11.11.2019.

Pilatotrama ljubarskyi (Pilát) Zmitrovich на пне лиственного дерева, кладбище Кировского района, единичная находка, 12.10.2019.

Pleurotus ostreatus (Jacq.) Р. Kumm. на пне лиственного дерева, кладбище Кировского района, единичная находка, 29.09.2019.

Psathyrella conopilea (Fr.) A. Pearson et Dennis на гнилой древесине, Алюминиевское кладбище, нередко, 13.10.2019; Центральное (Димитриевское) кладбище, нередко, 20.10.2019.

Pseudoclitocybe cyathiformis (Bull.) Singer на гнилой древесине, Алюминиевское кладбище, нередко, 13.10.2019.

Stropharia melanosperma (Bull.) Gillet на почве, Центральное (Димитриевское) кладбище, единичная находка, 20.10.2019.

Tulostoma brumale Pers. на почве, Центральное (Димитриевское) кладбище, единичная находка, 20.10.2019.

Заключение. Таким образом, в результате таксономического анализа микобиоты цеметериев Тракторозаводского, Центрального и Кировского районов города Волгограда было выявлено 17 вида грибов. Основным субстратом является древесина на различной стадии разложения: сухостойные стволы, валежные ветви, пни и гнилая древесина.
В дальнейшем планируется продолжить данное исследование.

\section{СПИСОК ЛИТЕРАТУРЫ}

1. Атлас-определитель дереворазрушающих грибов лесов Русской равнины / В.Г. Стороженко [и др.]. - М. : Товарищество науч. изд. КМК, 2014.$195 \mathrm{c}$.

2. Вишневский, М. В. Съедобные грибы и их несъедобные и ядовитые двойники: сравнительные таблицы / М. В. Вишневский. - М. : АСТ Астрель: Восток-Запад, 2010. - 48 с.

3. Змитрович, И. В. Определитель грибов России. Порядок афиллофоровые. Вып. 3 : Семейства ателиевые и амилокортициевые / И. В. Змитрович ; отв. ред. М. А. Бондарцева. - СПб. : Товарищество науч. изд. КМК, 2008. -278 с.

4. Ивойлов, А. В. Изучение видового разнообразия макромицетов : учеб.пособие / А. В. Ивойлов, С. Ю. Большаков, Т. Б. Силаева ; под общ. ред. А. Е. Коваленко, О. В. Морозовой. - Саранск : Издво Мордов. ун-та, 2017. - 160 с.

5. Лагугина, Т. В. Полная энциклопедия грибов России / Т. В. Лагутина. - М. : Рипол-Классик, 2017. $-320 \mathrm{c}$.

6. Леонтьев, Д. В. Флористический анализ в микологии / Д. В. Леонтьев. - Харьков : Ранок-НТ, 2008. $-110 \mathrm{c}$.

7. Мухин, В. А. Полевой определитель трутовых грибов / В. А. Мухин. - Екатеринбург : Издво УрГУ, 1997. - 104 с.

8. Переведенцева, Л. Г. Определитель грибов (агарикоидные базидиомицеты) / Л. Г. Переведенцева. - М. : Товарищество науч. изд. КМК, 2015. $119 \mathrm{c}$.

9. Семенов, Ю. Г. Полный иллюстрированный справочник грибника / Ю. Г. Семенов. - М. : МСП, 2001.-576 c.

10. Трутовые грибы : материалы междунар. курса по экологии и таксономии дереворазрушающих базидиомицетов в Центрально-Лесном заповеднике : учеб. пособие / В. М. Коткова [и др.]Хельсинки : Helsinki University Printing House, 2015.$95 \mathrm{c}$.

11. Bernicchia, A. Corticiaceae, s. 1/ A. Bernicchia, S. P. Gorjon // Fungi Europaei. - Alassio : Candusso Edizioni Italy, 2010. - Vol. 12. - 1008 p.

12. Guthmann, J. Heilende Pilze. Die wichtigsten Arten der Welt im Porträt/ J. Guthmann. - Wiebelsheim : Quelle et Meyer, 2017. $-423 \mathrm{p}$.

13. Laessoe, T. Mushrooms et Toadstools. The Illustrated Guide to Fungi / T. Laessoe. - L. : Dorling Kindersley Publishers Ltd, 2013. - 360 p. 
14. Lichtenauer, A. Pilze bei der Baumkontrolle: Erkennen Wichtiger Arten an Straßen-und Parkbäumen / A. Lichtenauer, T. Kowol, D. Dujesiefken. Braunschweig: Thalacker Medien, 2013. -64 p.

15. Niemelä, T. Torikseened Soomes ja Eestis (Estonian-Language Edition of the Finnish Original) / T. Niemelä. - Tartu : Eesti Loodusfoto, 2008. - 320 p.

16. Ryvarden, L. European Polypores. Part 1. Abortiporus-Lindtneria / L. Ryvarden, R. L. Gilbertson // Synopsis Fungorum. - Oslo : Fungiflora, 1993. Vol. 6. -387 p.

17. Ryvarden, L. European Polypores. Part 2. Meripilus-Tyromyces / L. Ryvarden, R. L. Gilbertson // Synopsis Fungorum. - Oslo : Fungiflora, 1994. Vol. 7. $-356 \mathrm{p}$.

18. Ryvarden, L. Poroid Fungi of Europe (with Photos by T. Niemelä and Drawings by I. Melo and T. Niemelä) / L.Ryvarden, I.Melo // Synopsis Fungorum. - Oslo : Fungiflora, 2014. - Vol. 31. - 455 p.

19. Ryvarden, L. The Genera of Polypores. Nomenclature and Taxonomy/L. Ryvarden // Synopsis Fungorum. - Oslo : Fungiflora, 1991. - Vol. 5. - 363 p.

20. Sunhede, S. Geastraceae. Morphology, Ecology, and Systematics with Special Emphasis on the North European Species // Synopsis Fungorum. Oslo : Fungiflora, 2014. - Vol. 1. -534 p.

\section{REFERENCES}

1. Storozhenko V.G., Krutov V.I., Ruokolajnen A.V., Kotkova V.M., Bondartseva M.A. Atlas-opredelitel' derevorazrushajushchikh gribov lesov Russkoj ravniny [Atlas-determinant of wood-destroying mushrooms in the forests of Russian Plain]. Msk., Tovarishhestvo nauchny izdanij KMK, 2014, 195 p.

2. Vishnevskij M.V. Syedobnye griby $i$ ih nesedobnye i yadovitye dvojniki: sravnitelnye tablicy [Edible Mushrooms and Their Inedible and Poisonous Counterparts: Comparative Tables]. Moscow, AST Astrel, Vostok-Zapad, 2010, 48 p.

3. Zmitrovich I.V. Opredelitel gribov Rossii. Poryadok afilloforovye. Vyp. 3: Semejstva atelievye $i$ amilokorticievye [Determinant of mushrooms in Russia. Order aphyllophorales. Vol. 3: Family televie and aminocarnitine]. Saint Petersburg, Tovarishhestvo nauchnykh izdatelstv KMK, 2008, 278 p.

4. Ivojlov A.V., Bolshakov S.Ju., Silaeva T.B.; pod obshh. red. Kovalenko A.E., Morozova O.V. (eds.) Izuchenie vidovogo raznoobraziya makromicetov: uchebnoe posobie [Studying the species diversity of macromycetes: tutorial]. Saransk, Izdatelstvo Mordovskogo Universiteta, 2017, 160 p.

5. Lagutina T.V. Polnaja jenciklopedija gribov Rossii [Complete Encyclopedia of Mushrooms in Russia]. Ripol-Klassik, 2017, 320 p.
6. Leontyev D.V. Floristicheskij analiz v mikologii [Floral analysis in Mycology], Kharkov, Ranok-NT, 2008, 110 p.

7. Mukhin V.A. Polevoj opredelitel trutovyh gribov [Field Guide Bracket-Fungus]. Ekaterinburg, Izdvo UrGU, 1997, 104 p.

8. Perevedentseva L.G. Opredelitel gribov (agarikoidnye bazidiomicety) [Determinant of Mushrooms (Basidiomycetes Agaricaceae)]. Moscow, Tovarishhestvo nauchnyh izdanij KMK, 2015. 119 p.

9. Semyonov Ju.G. Polnyj illyustrirovannyj spravochnik gribnika [Complete illustrated guide to the mushroom picker]. Moscow, MSP, 2001. 576 p.

10. Kotkova V.M., Niemelja T., Viner I.A., Shhigel D.S., Kurakov A.V. Trutovye griby: materialy mezhdunarodnogo kursa po jekologii $i$ taksonomii derevorazrushajushhih bazidiomicetov $v$ Centralno-Lesnom zapovednike: uchebnoe posobie [Polypore fungi: materials of the international course on ecology and taxonomy of lingnicolous basidiomycetes in the Central Forest reserve. Tutorial], Helsinki, Helsinki University Printing House, 2015.95 p.

11. Bernicchia A., Gorjon S.P. Corticiaceae s. 1. Fungi Europaei. Alassio, Candusso Edizioni, 2010, vol. $12,1008 \mathrm{p}$.

12. Guthmann J. Heilende Pilze. Die wichtigsten Arten der Welt im Porträt. Wiebelsheim Quelle et Meyer, 2017, $423 \mathrm{p}$.

13. Laessoe T. Mushrooms et Toadstools. The Illustrated Guide to Fungi. Dorling Kindersley Publishers Ltd, 2013, 360 p.

14. Lichtenauer A., Kowol T., Dujesiefken D. Pilze bei der Baumkontrolle: Erkennen wichtiger Arten an Straßen- und Parkbäumen. Braunschweig Thalacker Medien, 2013, 64 p.

15. Niemelä, T. Torikseened Soomes ja Eestis (Estonian-Language Edition of the Finnish Original). Eesti Loodusfoto Tartu, 2008, 320 p.

16. Ryvarden L., Gilbertson R.L. European polypores. Part 1. Abortiporus-Lindtneria. Synopsis Fungorum. Oslo, Fungiflora, 1993, vol. 6, 387 p.

17. Ryvarden L., Gilbertson R.L. European polypores. Part 2. Meripilus-Tyromyces. Synopsis Fungorum. Oslo, Fungiflora, 1994, vol. 7, 356 p.

18. Ryvarden L., Melo I. Poroid Fungi of Europe. Synopsis Fungorum. Oslo, Fungiflora, 2014, vol. 31. $455 \mathrm{p}$.

19. Ryvarden, L. The Genera of Polypores. Nomenclature and Taxonomy. Synopsis Fungorum. Oslo, Fungiflora, 1991, vol. 5, 363 p.

20. Sunhede S. Geastraceae. Morphology, Ecology, and Systematics with Special Emphasis on the North European Species. Synopsis Fungorum, Oslo, Fungiflora, 2014, vol. 1, 534 p. 


\section{БИОЛОГИЯ И БИОТЕХНОЛОГИЯ}

\section{Information About the Authors}

Nadezhda S. Kuragina, Senior Lecturer, Department of Biology, Volgograd State University, Prosp. Universitetsky, 100, 400062 Volgograd, Russian Federation, kuragina23@mail.ru.

Victoria S. Samokish, Student, Department of Biology, Volgograd State University, Prosp. Universitetsky, 100, 400062 Volgograd, Russian Federation, viktorya.samokish@yandex.ru.

\section{Информация об авторах}

Надежда Сергеевна Курагина, старший преподаватель кафедры биологии, Волгоградский государственный университет, просп. Университетский, 100, 400062 г. Волгоград, Российская Федерация, kuragina23@mail.ru.

Виктория Сергеевна Самокиш, студент кафедры биологии, Волгоградский государственный университет, просп. Университетский, 100, 400062 г. Волгоград, Российская Федерация, viktorya.samokish@yandex.ru. 